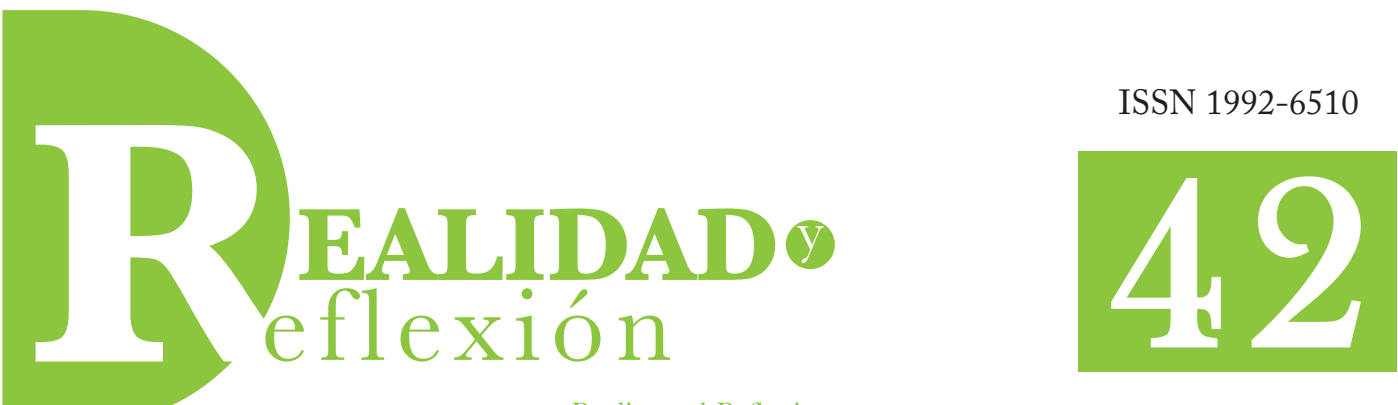

Reality and Reflection

Año 15, N 42, San Salvador, El Salvador, Centroamérica. Revista Semestral Julio-Diciembre 2015

Year 15, N 42, SAN Salvador, El SALVAdor, Central America. Semestral Journal July-December 2015

\title{
Los primeros diputados salvadoreños en redes sociales. Parlamentarios sin interacción
}

\author{
The first Salvadoran deputies on social networks. \\ Parliamentarians without interaction
}

\author{
Ana Evangelina Aguilar \\ Lcda. Periodismo y comunicaciones, \\ Universidad Centroamericana José Simeón Cañas, UCA \\ Máster en Asesoría de Imagen y Consultoría Política, \\ Universidad de Salamanca, España. \\ Investigadora para el área de comunicación ICTI-UFG. \\ aeaguilar@ufg.edu.sv
}

\section{RESUMEN}

El presente artículo busca contribuir con el análisis de las redes sociales digitales en el ámbito político, específicamente el parlamentario. Fue realizado a partir de un seguimiento de 3 años de los perfiles de Facebook, Twitter y YouTube de los diputados salvadoreños; y mediante el cual se llegó a la conclusión de que la mayoría de parlamentarios están desaprovechando esa herramienta de comunicación.

Palabras clave: Redes sociales, política, marketing político, Facebook, parlamento salvadoreño.

\section{ABSTRACT}

The objective of the present article is to contribute to the analysis of social networks in the political field, specifically in the Congress. The investigation took place during three years, in which Facebook, Twitter and YouTube accounts from salvadoran congressmen were followed up. The final conclusion from the research is that the congressmen are not taking full advantage of these means of communication.

Keywords: Social networks, politics, political marketing, Facebook, salvadorean congress. 


\section{Introducción}

En el mundo contemporáneo los procesos de comunicación a través del uso de herramientas técnicas que posibiliten la difusión y circulación de información se han tornado cada vez más indispensables para el funcionamiento y el mantenimiento de las democracias representativas. El cruce de la esfera política y el quehacer político con la comunicación es una herencia moderna explicada en la esfera pública (Habermas, 1991). Esta íntima relación ganó espacio gracias al rápido surgimiento y a la masificación de los medios de comunicación y fue enriquecida en gran manera por los medios digitales de comunicación. En El Salvador, pese a que en otras latitudes el uso de estos recursos era cada vez más habitual, fue hasta hace un par de años que el Órgano Legislativo logró consolidar sus medios institucionales de comunicación -radio y televisión legislativa-, así como su sitio web y sus perfiles de redes sociales institucionales. Ese proceso del Parlamento salvadoreño, de ampliar las formas de hacer publicidad y visibilizar sus actividades, provocó y ayudó a que muchos de los diputados de la legislación 2012-2015 vivieran una especie de efervescencia por crear o hacer uso de cuentas en redes digitales de comunicación como Facebook, Twitter y YouTube.

Con la llegada de internet, la comunicación individual se fue haciendo mucho más cercana, profunda y directa, ya que cada persona tiene la posibilidad de comunicarse con sus públicos a un bajo costo; eso sin mencionar la posibilidad de ganarse un espacio dentro de la esfera pública virtual. Para muchos parlamentarios a nivel mundial, dicha situación ha sido una perfecta oportunidad para acercarse a la población a través de sus páginas web personales; pero esto fue potenciado con la popularización de las redes sociales digitales, más notablemente de Twitter y Facebook. Así, por ejemplo, en El Salvador los números de personas conectadas a las redes sociales han ido en un rápido y pronunciado aumento en los últimos años.

De acuerdo con el más reciente informe de la empresa de mercadeo ANALITIKA (2015) la red social digital de Facebook es la más utilizada por los salvadoreños (98.6\%); le sigue YouTube con un $85.8 \%$ de preferencia, y en tercer lugar se encuentra Twitter con un 59.3\% de predilección entre la población.

Dichas estadísticas favorecen un enfoque que establece en la sociedad la percepción de que la interconexión proporcionada por la tecnología, más ahora a través de las redes sociales digitales, es capaz de promover cambios significativos en las maneras de comunicarse de los ciudadanos en su entorno social, cultural e incluso político.

Ahora bien, si así fuera, y de acuerdo a esta percepción, debería existir un cambio y generar más desarrollo de las prácticas políticas en nuestro país; ya que cuantos más ciudadanos están conectados de forma permanente a las redes sociales digitales, éstos también podrían estar conectados con sus representantes. Además, la política podría comenzar a configurarse y percibirse como transparente, observada $y$ monitoreada por la población desde sus entornos digitales. Y como resultado, incluso, podría verse como una política más ética, responsable y productiva. Las redes sociales digitales, por lo tanto, pondrían en el mismo plan de interacción y 
de diálogo a los ciudadanos y sus representantes, instrumentalizar las movilizaciones populares y, por último, garantizar la promoción de legislaturas más pluralistas y conscientes de la pluralidad de voces y discursos de la sociedad (Castells, 2012).

La tecnología puede, en estos casos, preparar el camino para que los ciudadanos obtengan información y los argumentos necesarios para el seguimiento de debates en el campo político y para que también puedan fiscalizar el destino de los recursos públicos; incluso, como ha sucedido en otras latitudes, puedan organizarse en protestas en plazas públicas fuera del medio virtual y poder mostrar así su indignación. Por lo tanto, es necesario contar con mucha claridad acerca de la amplia gama de usos que pueden tener estas nuevas tecnologías de la comunicación y así evitar que palabras como interacción sean usadas sin la debida y necesaria reflexión, trasladando razonamientos incrustados que apunten hacia una relación directa entre la mejora de la práctica política por sobre la cuestión técnica.

Así, en el diálogo directo, que se supone debería ser posible entre los representantes y representados por medio de las redes sociales digitales, el contenido del intercambio de información puede acabar reproduciendo prácticas políticas muy arraigadas en la sociedad salvadoreña. Por ejemplo, para Jesús Martín Barbero (2003) estas nuevas rutas, para el desarrollo de hacer política, significan romper con la aparente seguridad ofrecida por la reducción de los problemas que ofrecen las nuevas tecnologías de la comunicación. Teniendo en cuenta que la técnica de la comunicación a través de internet ha permitido el contacto directo, rápido, instantáneo y ha ayudado a dar forma a la esfera política que puede contener lazos de interacción y diálogo permanente con la sociedad, rompiendo, o al menos reduciendo, ciertas barreras. He aquí la importancia de mirar hacia atrás para ver el contenido de las redes sociales digitales, presente en la práctica comunicativa de los diputados de lo que se ha denominado como la primera legislatura 2.0 de El Salvador.

Para este estudio se recurrió a metodologías como la revisión bibliográfica, el monitoreo de las cuentas de los 84 diputados salvadoreños elegidos para el período 2012 - 2015, la cual comenzó con la elaboración de una base de datos de usuarios parlamentarios en las redes de Facebook, Twitter y YouTube, desde junio de 2012, y que finalizó con la legislatura en el mes de mayo de 2015, para luego realizar un análisis de la comunicación de estos en tres momentos específicos de cada año, la toma de juramento de los parlamentarios y cada aniversario de gestión de la legislatura.

Por último, se desarrolló la fase de recolección de datos, que se combinó con la observación del comportamiento y las actividades de las cuentas de los diputados, notas y observaciones sobre las formas adoptadas por los legisladores con la interacción o no interacción con los ciudadanos a través de las redes sociales digitales.

\section{Comunicación legislativa de los parlamentarios salvadoreños}

El Poder Legislativo salvadoreño se remonta al año de 1824, desde la fundación del régimen republicano centroamericano (2006). A partir de entonces, la comunicación ha sido uno de los 
elementos de prioridad en las prácticas políticas, con el fin de que las decisiones de los debates políticos pasen de la esfera de lo estrictamente político a la esfera de lo público.

De acuerdo a Jurgüen Habermas, para pasar del modelo político basado en el absolutismo hacia la representatividad, es esencial, en especial en países del continente europeo, trasladar la experiencia política a lo público, es decir, que la política tiene como condición para su funcionamiento la adición del público, trasladar de lo político a lo público las decisiones, discusiones, debates y puntos de vista. Es así como la visibilidad generada a partir de la publicidad comienza a jugar un papel central en el campo político.

La Asamblea Legislativa de El Salvador ha funcionado por muchos años comunicándose a través de publicaciones en los periódicos y medios de comunicación tradicionales, por medio de conferencias de prensa, y accediendo a que grupos de periodistas presencien discusiones de las comisiones de trabajo y debates en el Pleno Legislativo, lo que se puede considerar como las primeras formas de comunicación de los diputados con la ciudadanía; aunque éstas no incluían actividades o acciones propias y personalizadas del quehacer legislativo de cada diputado. A finales del año 2002 se inició con la impresión de la primera revista legislativa, que se editó con el fin de dar a conocer las actividades del Parlamento, sus presupuestos, trabajo de Comisiones, etc. Diez años después, en el 2012, la Asamblea Legislativa salvadoreña iniciaría con el uso de perfiles en sus redes sociales Facebook, Twitter y un canal en YouTube. Para el 2013, inauguró la Radio Legislativa, consolidando sus medios de comunicación en el 2014 con la creación de la Televisión Legislativa.

Por tanto, la paradoja de la representatividad se daba, tanto por la restricción de participación, como por la falta de identificación de los representantes de cada uno de los departamentos del país en la Asamblea Legislativa con sus representados, ya que los diputados no tenían acceso a través de los medios tradicionales de comunicación del Parlamento a comunicarse con sus votantes. En la esfera de comunicación legislativa, la modernización que tuvo el Congreso Salvadoreño desde el año 2012 al 2014 debería ir permitiendo procesos de interacción y comunicación de los diputados con la sociedad salvadoreña, de tal manera que se vuelve muy relevante la creación y apertura de perfiles institucionales del Parlamento en las redes sociales digitales, como parte de una estrategia de divulgación de las actividades y del trabajo que realizan los diputados de los distintos departamentos y partidos políticos.

Antes de que existieran las redes sociales digitales, como vehículo de divulgación, los diputados en algunos casos producían sus propios boletines de actividades, volantes, publicaciones escritas, etc. para distribuirlas entre sus votantes en los departamentos; además, aparecerían en entrevistas políticas de radio y televisión para informar a la población sobre sus iniciativas de Ley o propuestas. Hoy, con las redes sociales, aunque se continúa con la participación en los medios tradicionales de comunicación, muchos de los diputados publican y difunden información de las acciones que desempeñan dentro del Congreso y el trabajo partidario en sus departamentos, con el fin mantener informados 
a sus seguidores, demostrando que en nuestro país ambas herramientas de comunicación -tradicionales y digitales- se complementan.

Además, es importante destacar que la comunicación personalista no es una novedad propiciada por la tecnología; pero sí se ha visto profundizada por este tipo de prácticas y, quiérase o no, es capaz de generar una transformación significativa en la relación diputado y ciudadano a partir de la comunicación, sólo con el hecho de que ahora, existe una herramienta al alcance de los dos actores -representantes y representados-. De acuerdo con Recuero (2012) estas redes virtuales de comunicación poseen como característica el espacio que permite el envío de mensajes a un único individuo de manera reservada:

Esos recursos son extremadamente relevantes ya que generan un espacio seguro, es decir, un espacio donde es posible desarrollar conversaciones entre los actores y que estos están dispuestos a compartir con la red social. Estas conversaciones también parecen tener relevancia para el mantenimiento de los lazos sociales, una vez que permiten al actor enfocarse en un grupo menor dentro de su red, estrechando abi los componentes como confianza e intimidad.

Confianza e intimidad son sentimientos y expresiones que se desarrollan a través de la cercanía y del desarrollo de una relación personal, influenciada por diversos componentes, y que está muy lejos de cualquier connotación que remonte la impersonalidad característica del poder público. Ahora bien, el espacio privado en una red social digital es sobre todo individual, personal, estrecha y próxima, o al menos de esta manera es promovida por los usuarios de algunas redes sociales, lo que puede llevar a que el ciudadano retome dicha premisa con el fin de intercambiar mensajes de diferentes situaciones con sus representantes en el Congreso Salvadoreño.

De esta manera, una herramienta tecnológica puede ser utilizada de distintas formas, con varios objetivos y siguiendo ciertas estrategias. Estas herramientas de comunicación incluso pueden acondicionar una práctica social más democrática y encaminada a la vigilancia de los temas de interés colectivo de la esfera política. Por otra parte, la conexión directa de las personas, por medio de estas redes virtuales, también puede ocasionar la profundización de una práctica que necesita de mayor intimidad y creación de lazos afectivos entre representantes y representados, ciudadanos e instituciones, un quebranto en las jerarquías formales de comunicación, al que los salvadoreños hemos estado acostumbrados, es decir: cuestionar a nuestros funcionarios.

Las redes sociales nos permiten y dan espacio a que como ciudadanos emplacemos a nuestros funcionarios públicos, que cuestionemos sus acciones y decisiones; a la vez que generan la posibilidad de que nuestros representantes nos expliquen y expongan sus puntos de vista. Son una herramienta en la que se puede cuestionar y responder, proponer y promover. Una herramienta que influye en ambas vías de construcción de la comunicación.

\section{Los diputados en sus redes sociales}

De muchas funciones de la comunicación, en las redes sociales de los diputados salvadoreños sólo puede observarse una: la relativa a la 
difusión. Otras funciones como la interacción y la vinculación no son utilizadas por los parlamentarios en sus perfiles, es decir que la posibilidad de construir lazos afectivos más directos con la población y que permitan la posibilidad de un diálogo entre los usuarios es desperdiciada por los diputados que tienen perfiles en redes sociales digitales.

En dichas redes virtuales de comunicación el espacio físico ya no es una barrera, ya que el intercambio de mensajes y el establecimiento de un diálogo se pueden desarrollar en cualquier momento. Como consecuencia, un ciudadano no necesita desplazarse hasta las oficinas departamentales del partido de su preferencia o dirigirse a la oficina del diputado para expresarle sus preguntas, dudas, peticiones o comentarios. Así, en cualquier instante, el funcionario público puede ser abordado; y en dicho abordaje, diversos intereses están en juego y determinan su contenido, sea con situaciones colectivas de mucha amplitud, temas de interés directo de un grupo específico, o incluso, solicitudes de carácter privado.

Hay que recordar que según la Constitución de la República de E1 Salvador que está vigente, la Asamblea Legislativa salvadoreña es un cuerpo colegiado y que se compone de 84 diputados, todos elegidos por voto popular directo, según el sistema de representación proporcional para un período de tres años. Así que, para este estudio, en primer lugar, se identificaron las redes sociales con las que iniciaron y finalizaron los diputados del periodo 2012-2015 de la Asamblea Legislativa en las redes sociales en Facebook, Twitter y YouTube. Luego se monitorearon las cuentas existentes, durante la semana en que se cumplía un aniversario de gestión legislativa, con el fin de registrar las publicaciones realizadas, así como la posible interacción. (Ver Gráfico 1).

Así, el 85\% de los diputados salvadoreños, período 2012-2015, contaron con al menos un perfil en cualquiera de las tres redes sociales virtuales analizadas; un 15\% de parlamentarios en ningún momento creó perfiles en una red social digital. Sin duda, del inicio al final hubo un incremento en el uso de redes sociales digitales con el fin de informar a la población.

Es importante recordar que cada una de dichas herramientas de comunicación digital posee una forma diferente de comunicarse con sus usuarios. A veces, los usuarios de Twitter y Facebook coinciden cuando se trata de buscar cierto perfil de audiencia; pero el comportamiento de esas audiencias es distinta en las redes digitales. Por ejemplo, algunos utilizan Facebook como una red social de uso propio, compartiendo fotos y publicaciones más personales y entre gente más cercana; Twitter se enfoca hacia un contacto más externo (Oliver, 2015).

Por tanto, y porque son redes diferentes con perfiles de usuarios distintos y aplicaciones diferentes, en cada una de las redes sociales se debe individualizar lo que se publica $\mathrm{y}$ no vincular las redes digitales como muchos de los diputados salvadoreños han hecho en sus perfiles de Facebook y Twitter, desaprovechando así la posibilidad de comunicarse con distintos tipos de usuarios que tienen diferentes necesidades informativas y de comunicación. 


\section{Gráfico 1}

Comparativo de cuentas de diputados creadas en redes sociales del inicio y final de la legislatura 2012-2015

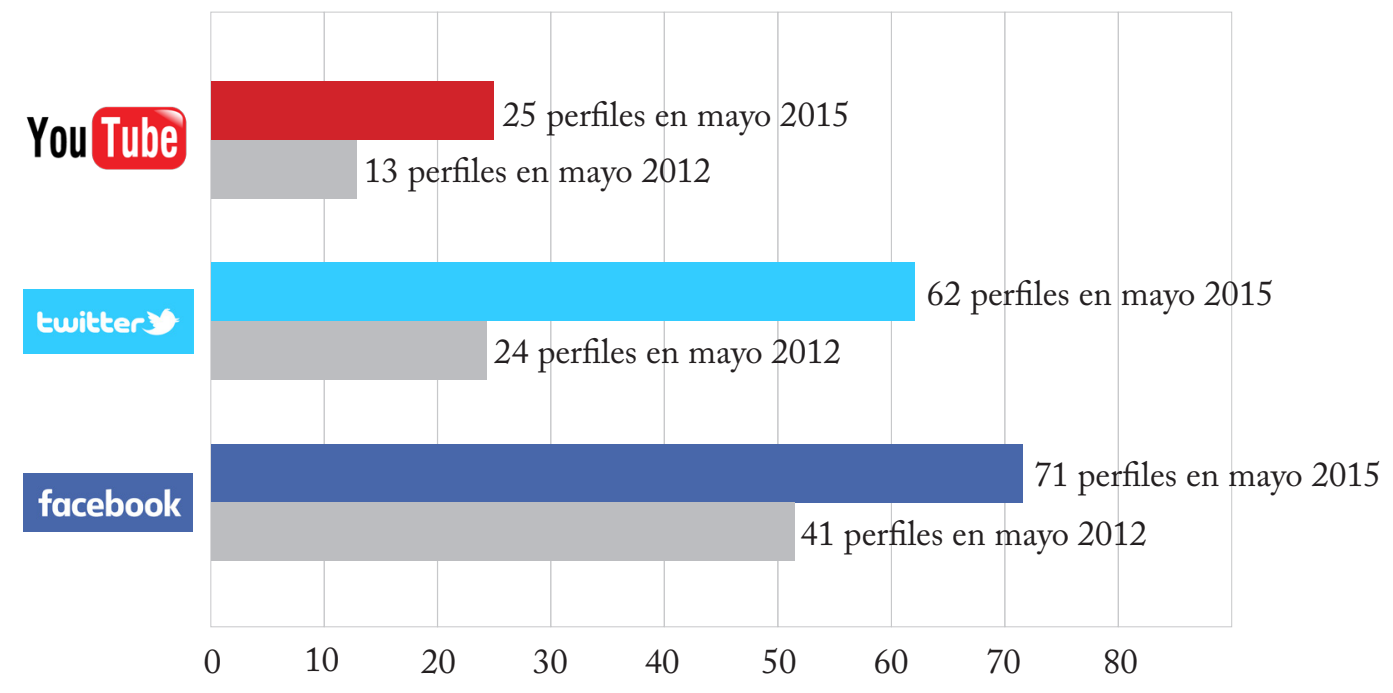

Fuente: elaboración propia.

En cuanto a la actualización de información que realizan los diputados en sus redes sociales virtuales, cabe aclarar que YouTube es la red más abandonada, no sólo porque menos de la mitad de los parlamentarios la utilizan, sino porque las actualizaciones tenían un promedio de un video cada tres o seis meses. En cambio, en Facebook y Twitter tienen una actualización mucho más frecuente. (Ver Gráfico 2).

Ahora bien, existe una situación que en algunos casos puede darse entre los funcionarios como los diputados, y es que contratan personal para que publique en nombre de ellos en sus redes sociales. Así por ejemplo, en sitios o canales como YouTube, como el formato tiende a ser más próximo al periodismo, con una interacción un poco más técnica, entonces se pública en ese mismo tono. En cambio, los perfiles de Twitter y Facebook son marcados por un lenguaje más coloquial, lo que obliga que una persona contratada para esa labor escriba en primera persona, lo que crea expectativa de que es el propio diputado es el que está utilizando la red, pero pese a esa característica, se verificó que muchas veces esto no sucede así, más bien es una estrategia adoptada por el equipo de comunicaciones o asistentes de algunos parlamentarios, con la intención de crear mayor proximidad con los usuarios.

Una de las características que componen la formación de las redes sociales online está relacionada con la calidad de los lazos sociales que se construyen (Amaral, Fragoso, 


\section{Gráfico 2}

Actualización de información de redes sociales de los diputados salvadoreños

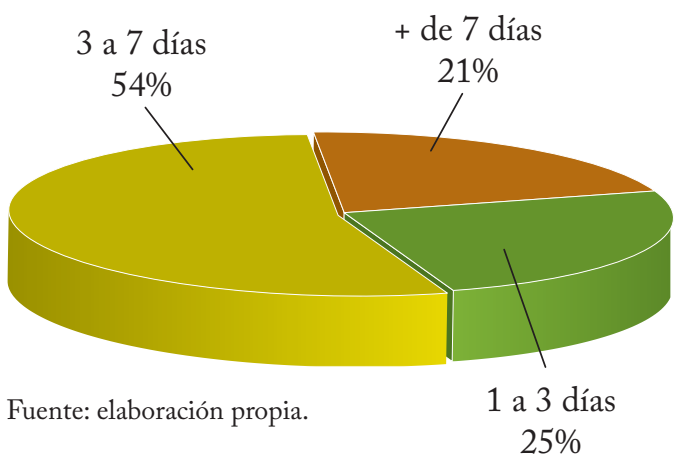

\& Recuero, 2012), de tal manera que si un ciudadano quisiera tener información sobre la gestión de un diputado podría buscar en Internet; pero también podría buscar en sus redes sociales algo más importante, desde el punto de vista de la democratización de la esfera política. Debería utilizarse para dialogar e intercambiar puntos de vista con los usuarios y entre estos, y no sólo para divulgar información.

En el caso de los diputados salvadoreños, no hacen más que publicar información de lo que están haciendo los fines de semana con sus partidos políticos, las actividades que desarrollan en su papel de parlamentarios a diario, y algunos que comparten su vida familiar y social con sus seguidores.

Muy pocos son los que responden a cuestionamientos o puntos de vista que los usuarios intercambian con ellos, convirtiendo sus redes sociales en meras vitrinas de información, mas no de interacción.

\section{Gráfico 3}

Interacción de diputados con sus seguidores en redes sociales

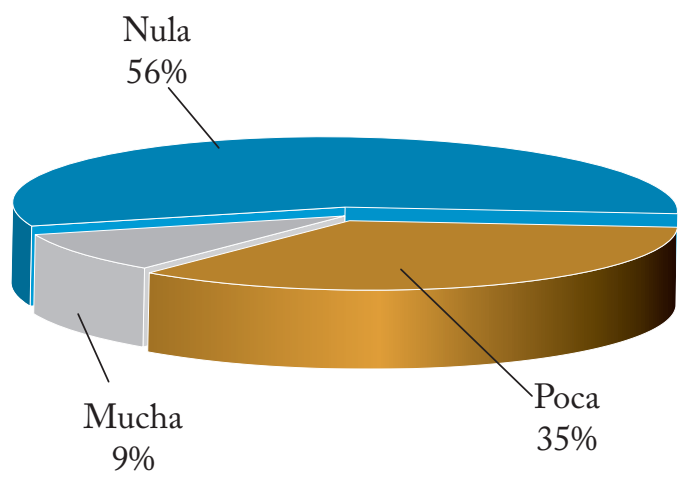

Fuente: elaboración propia.

Por tanto, no se cumple el elemento diferencial propuesto por las redes sociales digitales, que es justamente permitir a los ciudadanos el tener expectativas sobre la cercanía de un parlamentario, es decir, el representante que está presente en un espacio abierto a los cuestionamientos y al diálogo.

Ahora bien, más allá de la cuestión de gramática, en la que las publicaciones del diputado en sus redes sociales se publican en primera persona del singular, con el fin de hacer creer a sus seguidores que es él quien está informando, y no su equipo de comunicaciones el que publica en su nombre, sumado a la dinámica singular de Twitter y Facebook, la presencia de una de las características de la cultura política salvadoreña es más que evidente: la falta de comunicación entre los ciudadanos con sus representantes, es decir que, aunque las redes sociales sean una herramienta ideal para construir redes y relaciones cercanas entre gobernantes y gobernados, la dinámica político-cultural de no acercamiento 
a los ciudadanos es muy evidente en el manejo que los parlamentarios han hecho de sus redes sociales digitales en esta denominada primera legislatura salvadoreña 2.0.

Entonces, el lazo social que debería generarse por medio de las redes sociales online, es la de una especie de relación individual y personalizada, el intercambio de mensajes, etc., como una estrategia de comunicación que posibilite generar intimidad entre los parlamentarios y los ciudadanos; esto por hoy no existe.

Recordemos también que un canal de diálogo directo con el ciudadano por las redes sociales online lo constituyen los mensajes intercambiados por las mismas redes y que pueden darse básicamente de dos maneras: pública y privada. La pública es aquella que puede ser vista por otros usuarios, aparte de los sujetos directamente involucrados (usuario y seguidor). Sin embargo, tanto Twitter como Facebook tienen la posibilidad de que los perfiles sean modificados para que no se puedan recibir mensajes directos o privados de terceros. De acuerdo con Raquel Recuero (2012) "Dichas conversaciones privadas también parecen tener relevancia para el mantenimiento y profundización de los lazos sociales, ya que le permiten al seguidor ser parte de una red aún más estrecha del usuario, lo que provoca en los seguidores componer una relación más cercana con el usuario". El espacio privado de una red social es sobre todo individualizado, personal, estrecho y muy próximo... o al menos esa debe de ser la expectativa entre los usuarios, especialmente en aquél que inicia el diálogo reservado para esos escondrijos virtuales; pero ¿Qué pasa cuando los ciudadanos no tienen la posibilidad de ser parte de ese círculo tan estrecho de seguidores?
La posibilidad de generar confianza e intimidad entre los usuarios se ve desperdiciada una vez más, y por tanto las posibilidades de generar acercamientos en la red social son desaprovechadas por los parlamentarios y sus equipos de comunicación.

\section{Conclusiones}

La comunicación de los parlamentarios salvadoreños hasta hace un par de años ha tomado fuerza. No sólo desde el punto de vista institucional sino que también personal; pero falta mucho para que estas herramientas de comunicación puedan adoptar una dinámica y un lenguaje personalizado que sea significativo en la relación diputado y ciudadano. Con las nuevas tecnologías de la comunicación y las redes sociales online deberíamos de tener una profundización de la construcción de relaciones y deberían estar marcadas por el aprovechamiento de dichas redes por los parlamentarios, pero no es así. Las herramientas están siendo desaprovechadas tanto por los legisladores como por los equipos de comunicación.

Las redes sociales de los diputados están muy profundamente marcadas por la práctica cultural, muy propia de la sociedad salvadoreña, la desvinculación del político con el ciudadano, la misma desvinculación reflejada en la no interacción entre representantes y representados en las redes sociales digitales. Los perfiles de las redes sociales de los parlamentarios que divulgan sus acciones, no son nada más que eso: perfiles de divulgación y no plataformas de diálogo con la sociedad.

Aunque los diputados en sus perfiles publiquen en primera persona, no necesariamente significa 
que sea el mismo diputado quien publique; también cabe la posibilidad de que sean miembros de su equipo de comunicación los que están actualizando las redes sociales del parlamentario; aun así, esta práctica demuestra la necesidad del diputado de divulgar sus actividades y acciones en las redes sociales digitales, ya que contrata personal específico para el manejo de éstas, algo que no todos los diputados hacen.

La comunidad de seguidores que muchos de los diputados han logrado reunir en cada una de sus redes sociales online, no refleja el interés que el parlamentario tiene de relacionarse con sus seguidores; es decir, que aunque tengan muchos seguidores e incluso ellos -los diputados- puedan seguir a varios usuarios, no están interesados en dialogar o intercambiar posturas políticas o de cualquier otra índole. Los diputados le han dado más importancia a obtener cantidad de seguidores, que comunicarse con estos. Así, ser el diputado que más publica en Facebook o más tuitea, no significa que los mensajes sean de calidad; ya que los congresistas no interactúan con sus seguidores, no contestan preguntas o dudas y mucho menos aceptan debate de ideas.

Por otro lado, un buen número de diputados salvadoreños abandonó sus cuentas en redes sociales una vez finalizada la campaña electoral. Lo que demuestra y deja entredicho la utilización que hicieron de las mismas durante la campaña electoral, puesto que sólo utilizaron sus perfiles digitales convenientemente en época electoral y dejando de lado la comunidad que pudieron construir, desaprovechando también la oportunidad de propagar continuamente sus propuestas e iniciativas.

\section{Bibliografía}

Amaral, A., Fragoso, S., \& Recuero, R. (2012). Métodos de Pesquisa para Internet. Metodista. Brasil

ANALITIKA. (enero de 2015). Obtenido de http://www.analitika.com.sv/main/ wp-content/uploads/2015/01/Estudio-deRedes-Sociales-2015-Analitika-MarketResearch.pdf

Asamblea Legislativa de El Salvador. (2006). Historia del Órgano Legislativo de la República de El Salvador. San Salvador: Albacrome.

Castells, M. (2012). Redes de indignación y esperanza: los movimientos sociales en la era de internet. Alianza Editorial.

Castells, M. (2006) La sociedad red: una visión global. Alianza Editorial.

Fernéndez parada, A. (2014) Interactividad y Redes Sociales. Editorial ACCI. Madrid.

Habermas,J.(1991).The structural transformation of the public sphere. MIT Press.

Martín-Barbero, J. (2003). De los medios a las mediaciones. Colombia: Nomos S.A.

Oliver, B. (enero de 2015). Estrategias en Twitter y Facebook: ¿iguales o aplicadas a cada red? Obtenido de: http://tendenciasweb.about. com/od/el-trabajo-y-la-web/a/EstrategiasEn-Twitter-Y-Facebook-Iguales-OAplicadas-A-Cada-Red.htm 
Pérez Barber, V. (2010) El político en la Red Social. Editorial Club Universitario.

Recuero, R. (2012). Conversação em Rede: Comunicação Mediada pelo Computador e Redes Sociais na Internet. Porto Alegre: Sulina.
Requena Santos, F. (2003) Análisis de Redes Sociales. Orígenes, teorías y aplicaciones. Centro de Investigaciones Sociológicas. Madrid. 